University of Nebraska - Lincoln

DigitalCommons@University of Nebraska - Lincoln

$11-2007$

\title{
Illuminating a cross-cultural leadership challenge: When identity groups collide
}

Donna Chrobot-Mason

University of Cincinnati, donna.chrobot-mason@uc.edu

Marian N. Ruderman

Center for Creative Leadership, ruderman@ccl.org

Todd J. Weber

University of Nebraska-Lincoln, drawkcab321@gmail.com

Patricia J. Ohlott

OMG Center for Collaborative Learning, Philadelphia, PA

Maxine A. Dalton

Hot Springs, NC

Follow this and additional works at: https://digitalcommons.unl.edu/leadershipfacpub

Part of the Management Sciences and Quantitative Methods Commons

Chrobot-Mason, Donna; Ruderman, Marian N.; Weber, Todd J.; Ohlott, Patricia J.; and Dalton, Maxine A., "Illuminating a cross-cultural leadership challenge: When identity groups collide" (2007). Leadership Institute Faculty Publications. 2.

https://digitalcommons.unl.edu/leadershipfacpub/2

This Article is brought to you for free and open access by the Leadership Institute at DigitalCommons@University of Nebraska - Lincoln. It has been accepted for inclusion in Leadership Institute Faculty Publications by an authorized administrator of DigitalCommons@University of Nebraska - Lincoln. 


\title{
Illuminating a cross-cultural leadership challenge: When identity groups collide
}

\author{
Donna Chrobot-Mason, ${ }^{1}$ Marian N. Ruderman, ${ }^{2}$ Todd J. Weber, ${ }^{3}$ \\ Patricia J. Ohlott, ${ }^{4}$ and Maxine A. Dalton ${ }^{5}$ \\ ${ }^{1}$ University of Cincinnati, Center for Organizational Leadership, 6408 French Hall, PO Box \\ 210094, Cincinnati, OH 45221-0094, USA; email donna.chrobot-mason@uc.edu \\ 2 Center for Creative Leadership, PO Box 26300, Greensboro, NC 27438-6300, USA; tel 336 \\ 288-7210, fax 336 286-4434 \\ ${ }^{3}$ University of Nebraska-Lincoln, Gallup Leadership Institute, 114 College of Business Ad- \\ ministration, Lincoln, NE 68588-0497, USA; email tweber2@unl.edu \\ ${ }^{4}$ OMG Center for Collaborative Learning, 1528 Walnut St., Suite 805, Philadelphia, PA \\ 19102, USA; tel 215 732-2200 \\ 5749 D and G Road, Hot Springs, NC 28743, USA
}

\begin{abstract}
When societal conflicts between social identity groups spill over into organizations, leaders face the formidable challenge of attempting to bridge differences and manage the conflict in order to accomplish work. After reviewing the literature on intergroup conflict, workplace diversity and social identity theory, we examine four potential leadership strategies for managing identity-based conflicts. The four leadership strategies are decategorization, recategorization, subcategorization and crosscutting. Examples drawn from an interview-based study are used to illustrate theoretical constructs found in the literature. We then consider each of these strategies in cross-cultural contexts and generate propositions to reflect differences in the effectiveness of the strategies in collectivist versus individualist cultures.
\end{abstract}

$\mathrm{T}$ he challenge of managing interpersonal and resource-based conflict in organizations has been well documented (e.g. Amason and Schweiger, 1997; Jehn, 1995; Rahim, 2001). However, an even more complex, intense and disruptive type of conflict seems to be emerging in the workplace as a significant challenge for organizational leaders. Identity-based conflicts, involving disputes over the intrinsic value of the social groups with which individuals identify, often originate outside of the work context, but they emerge as workers from various identity groups in conflict attempt to work together. The conflicts embedded in society literally spillover into the organization influencing work processes and practices. In this paper, we begin to illuminate the unique challenges leaders face in attempting to prevent identity-based conflicts from emerging and escalating.

Our work is based on a review of the literature and illustrated with examples from interviews with leaders conducted as part of a pilot study. Based on an examination of literature in the areas of intergroup conflict, workplace diversity, and social identity theory, we identified the critical constructs and models applicable to this leadership challenge. In the first part of this paper, we discuss four strategies identified by the social identity literature: decategorization, recategorization, subcategorization and cross- 
cutting. In the second part, we discuss the relationship of these strategies to cultural differences. In doing so, we have identified a critical gap in the current literature. To date, there has been very little discussion of the role of cultural context in determining an appropriate and effective leadership strategy for preventing conflict between social identity groups. Therefore, our unique contribution to the leadership literature based on this multidisciplinary literature review is to offer research propositions for future work in this area as well as identify potential "blind spots" such as the importance of taking cultural factors into account when managing social identity conflict in the workplace.

In addition to reviewing the literature, we spoke with 24 individuals in leadership positions in various countries to get their first hand accounts of what it is like to lead in the context of very salient social identity group differences. These stories are used in the paper for illustrative purposes only. Drawn from nine different countries, the interviewee accounts bring to life constructs discussed in the literature.

\section{The leadership challenge}

For decades now, researchers have been predicting that globalization, increased technology, civil rights legislation and changing demographics would create new challenges for leaders who must manage a diverse workforce (e.g. Chrobot-Mason, 2003; Jackson, 1992; Morrison, 1992). All of these factors have significantly increased the likelihood that workers from both genders, various nationalities and ethnic backgrounds, multiple races, and a variety of religions will be required to work together.

Robert House and Global Leadership (2004) argue that organizations must consider cultural differences as the globalization of business continues to increase. He states that "as economic borders come down, cultural barriers go up, thus presenting new challenges and opportunities in business. When cultures come into contact, they may converge on some aspects, but their idiosyncrasies will likely amplify" (House and Global Leadership and Organizational Behavior Effectiveness Research Program, 2004: 5). In this paper, we examine conflicts that emerge due to historically deeprooted boundaries and tensions between social identity groups, which create unprecedented leadership challenges in today's workplace.

Social identity conflicts can be distinguished from interpersonal disagreements by the nature of the causal attributions made by the disputants and by the amplification of the event to a larger collective (Simon and Klandermans, 2001). In other words, a disagreement may begin between two people but in a social identity conflict, at least one party attributes causality to the social identity and intergroup history of the players, not to individual differences. When at least one party attributes a conflict event to race, gender, religion, sexual orientation, nationality or ethnicity, and takes sides based on their own race, gender, religion, sexual orientation, nationality, or ethnicity, this is a social identity conflict.

Friedman and Davidson (2001) contend that it is important to consider identity groups within a social power structure and that not all groups hold equal status within a particular societal context. Whereas some social identity groups are privileged, others are systematically disadvantaged and hold a position of lower status and power within society. Due to the centrality of social identity, its importance to the development of a healthy self-concept, and the inequalities that exist between social identity groups in most societies, social identity conflicts are charged with emotion, difficult to resolve and often intractable. "When identities are intertwined with shared ideologies, the stakes in a conflict are much greater and the costs of reaching a resolution are much higher than for conflicts not rooted in group membership" (Putnam and Wondolleck, 2003: 43). In general, intergroup conflict emerges either as a re- 
sult of competition over scarce resources or a reaction to a perceived threat posed by an "evil other" (Himes, 1980; Katz, 1964; Rothman, 1997). Unlike resource or interestbased types of conflict which are typically well-defined and may be resolved through compromise, identity-based conflicts involve disputes over the intrinsic value of the social group with which individuals strongly identify, and consequently the individual's own value is at stake (Cavey, 2000; Hicks, 2001). As a result of the importance of the conflict to the essence of the individual's existential value, these conflicts are usually resistant to resolution and can quickly escalate (Putnam and Wondolleck, 2003).

To illustrate these phenomena in the workplace, let us draw from an interview conducted in Mozambique. The story involves tension between Portuguese and Africans in a large multinational corporation. In the organization, the Portuguese still hold the majority of positions of power. For five centuries, Mozambique was a Portuguese colony. Liberation from Portugal took place in 1975 after a protracted war. This was followed by a civil war, famine and severe economic problems. Mozambique became a democracy with the 1990 constitution, giving rights to all. Racial tensions reflect this legacy of colonization and slavery. In addition, Mozambique has been drawn into the struggles against white rule in South Africa and Rhodesia.

The interviewee tells the story of a black receptionist who is approached by the wife of a white, Portuguese expatriate senior director. The white woman asks to see her husband, which violates a corporate policy forbidding employees to receive personal visits during work hours. The black receptionist refers to the policy and refuses the visit, which angers the white woman. She proceeds to phone her husband, who then angrily approaches the receptionist, yelling at her and using racial slurs to denigrate her. The interviewee then tells how the conflict escalates as black employees approach the white director to tell him he was wrong. The white director then proceeds to write a memo. to another white senior vice president, who punishes the black receptionist for her behavior. The conflict continues to escalate even further as another black staff member (a cleaner) takes the story to the media and the labor authorities. Eventually, the department of foreign affairs intervenes. The interviewee describes this conflict as the "tip of the iceberg" rather than an isolated event because there is a longstanding history of conflict between these two groups ever since the time the Portuguese ruled Mozambique. This story clearly depicts how a societal conflict between two identity groups can spill over into the work context such that group members begin to take sides and attribute the cause of the conflict to negative intergroup history rather than an isolated disagreement between two individuals.

To summarize, leaders face a unique challenge when members of social identity groups who have historically been deeply divided by race, ethnicity, religion, social class, region, etc. come together in the workplace and are divided as a result of some dispute in which the cause is attributed to social identity differences and the dispute is then amplified to a larger collective. In the next section, we review literature on Social Identity Theory (SIT), inter-group anxiety, faultlines and conflict escalation, to illustrate further the challenges leaders face when attempting to resolve a social identity conflict at work.

\section{Literature review}

\section{Social identity theory}

Psychological theory and research suggest that people tend to have strong needs for both inclusion and differentiation (Brewer and Brown, 1998). Belonging to social groups seems to satisfy both needs by allowing the individual to belong to some larger collec- 
tive as well as distinguishing oneself from members of other groups. Social identity theory may be used as a basis for understanding the positive and negative outcomes that result when members of different identity groups interact. Social identity theory presumes that an individual's self-concept is derived from membership in a social group together with the psychosocial value and emotional significance attached to that membership (Turner and Giles, 1981). The theory suggests that individuals engage in a cognitive process in which they classify themselves and others into categories or groups. This categorization process serves two functions: (a) it provides individuals with a systematic means of defining others, and (b) the individual is able to define him- or herself within the social environment (Ashforth and Mael, 1989). In general, these theories suggest that people evaluate the social groups to which they belong as positive and are motivated to maintain such evaluations in order to preserve a favorable self-image.

\section{Inter-group anxiety}

The historical legacy of conflict between identity groups may strongly influence the extent to which conflict emerges in the workplace. For example, the intensity and duration of previous conflicts may influence the emergence of continued conflict between identity groups. This phenomenon, known as intergroup anxiety (Stephan and Stephan, 1985), is created by three sets of factors: prior intergroup relations (e.g. the amount and conditions of prior contact); prior intergroup cognitions (e.g. knowledge of the outgroup, stereotypes, prejudice, expectations and perceptions of dissimilarity); and situational factors that characterize the intergroup interaction (e.g. amount of structure, type of interdependence, group composition, relative status). The anxiety stems from the anticipation of negative consequences or comparisons as a result of having been in contact with the other group (Fisher, 1990; Stephan and Stephan, 1985). Consequences of intergroup anxiety may include avoidance of intergroup interaction, information processing biases (e.g. seeking information to confirm existing stereotypes), heightened emotional responses to outgroup members (e.g. overreaction to even slight provocations) and stronger positive ingroup bias that results from a perceived threat to self-esteem, all of which may increase the likelihood of identity-based conflict (Stephan and Stephan, 1985). Intergroup anxiety thus can be a primer for conflict within the organization and the more entrenched and historically volatile intergroup relations have been in the past, the more difficult it will be for the leader to bridge differences and manage social identity conflict effectively. In our previous example, the political history of the conflict between Portugal and Mozambique resulted in a generalized distrust between these two groups, serving as a primer for conflict within the organization.

\section{Faultlines}

Identity group representation or composition within the workplace may serve to "activate" or evoke categorization and thus increase the potential for conflict between identity groups. Lau and Murnighan (1998) proposed a concept they call faultlines to examine the underlying patterns of group member characteristics that can be an important determinant of subgroup conflict. "Group faultlines are hypothetical dividing lines that may split a group into subgroups based on one or more attributes" (Lau and Murnighan, 1998: 328). Gender faultlines, for example, divide a work group's members into male and female subgroups.

Faultlines in work groups are similar to faultlines in the earth's crust in that group members' many demographic dimensions resemble multiple layers, they may go unnoticed without the presence of external forces, and strong faultlines provide an op- 
portunity for work groups to crack open, revealing the importance of their attributes. Faultlines may be activated by topics, issues or events that make certain social identities particularly salient (see Powell and Taylor, 1998, for an example). For example, affirmative action issues may activate racial divisions, political reform debates may activate liberal and conservative identities, and gender faultlines may be activated when workplace sexual harassment is discussed. However, recent research suggests that communication in work groups with strong faultlines may prove problematic even when the group's task and faultlines are unrelated (Lau and Murnighan, 2005). In other words, the mere presence of these social identity differences can make teamwork difficult.

The faultlines model (Lau and Murnighan, 1998) provides a useful analogy for understanding the challenges that leaders of demographic diversity must confront. When faultlines exist within the organization because of diversity, there is significant potential for social identity groups to polarize (Simon and Klandermans, 2001; Wetherell, 1987) such that battle lines will be drawn along those faultlines and work may be negatively impacted. Returning to our Mozambique example, it is easy to see how the intergroup anxiety between the Portuguese and Mozambicans sets the stage for group polarization and the racial slur activated the faultline between whites of Portuguese ancestry and blacks of African ancestry in the organization. In situations where there is a long history of distrust and contempt between groups in the society and intergroup anxiety is high, the mere presence of these faultlines may pose problems for the leader. For example, in Israel where there is a long and deeply rooted history of intense conflict between Palestinians and Israelis, faultlines in an organization might easily erupt into social identity based conflicts. One of our interviewees told a story about a strong Israeli/Palestinian faultline in a hospital workforce. The interviewee described the work environment as one in which the underlying conflict and tension was ever-present. In less extreme situations, for example where intergroup anxiety is moderate, faultlines in the organization may be activated by an external event that occurs in the society or an event occurring inside the organization, which serves to make identity group differences and intergroup anxiety salient and thus leads to group polarization. Once group polarization occurs, the scope of the leadership challenge depends largely on the extent to which the conflict escalates or dissipates.

\section{Conflict escalation}

The process of escalation is well documented in the conflict literature. Northrup (1989) outlines a series of stages (threat, distortion, rigidification and collusion) in which he describes the role of identity in conflict escalation. During the first stage, an event occurs that is perceived as invalidating to the core sense of identity for group(s) involved, which is experienced as a serious threat. In the second stage, distortion, group members attempt to psychologically respond to the threat, often by denying or redefining the incident in order to maintain the core sense of identity. In the third stage, rigidification, perceptions of threat increase resulting in greater polarization where ingroup/outgroup distinctions become increasingly exaggerated and rigid, and dehumanization may result. During the final stage, parties collude in maintaining the conflict and the conflict becomes institutionalized such that the social identity of the group becomes interwoven with the conflict itself. At least some of these stages of conflict are apparent in our Mozambique example, beginning with the racial slur that is experienced as a threat by black employees, followed by greater polarization and intergroup distinctions as both black and white employees begin to take sides and involve others at higher levels in the organization. 


\section{Leading across social identity differences}

When social identity conflicts emerge in the workplace, it seems that organizational members turn to leaders for help. In this paper, we define leaders as individuals with formal organizational authority who engage in processes and actions that lead to shared direction, alignment and commitment ( $\mathrm{O}^{\prime}$ Connor and Quinn, 2004; Van Velsor and McCauley, 2004). Employees expect leaders, persons with formal authority, to intervene when social identity conflicts emerge. One of our interviewees illustrates this point by saying, "They look to us as the leadership of the program to create an environment that lessens that struggle, lessens that conflict." Leaders' reactions to identity-based conflicts have the potential to either de-escalate the conflict situation or polarize social identity groups even further. Therefore, the role of the leader in such situations is particularly important. However, the leadership literature suggests that the role of the leader is particularly challenging, given that he/she is also a member of one of the social identity groups.

Haslam (2001) proposes that a particular group member will be perceived as prototypical of his/her group to the extent that the person is similar to members of his/ her own group and different from members of other groups. Turner (1987) suggests that the group member who is most likely to exercise leadership and exert influence is the one who represents the strongest in-group prototype; that is, the one who is most representative of the shared social identity of the group. Research suggests that liking, or attraction, increases compliance with requests (Berscheid and Reis, 1998). The most prototypical person is able to influence because he or she is socially attractive to the other group members who are thus more likely to agree and comply with suggestions. Further, a cycle results in which the ability of the leader to influence the group increases as the attributions of leadership made by others increase. Through their compliance, the group publicly endorses the leader, imbues him or her with greater status and prestige, and thus increases the leader's power to influence (Hogg, 2001). In a conflict situation social identity becomes more salient (Tsui and Gutek, 1999) and members can be expected to confer leadership increasingly on those whom they perceive to best embody the position of their ingroup (Fielding and Hogg, 1997; Hogg, 1996).

\section{Literature review summary and workplace implications}

Based on the literature review and the interviews we conducted, we believe social identity conflicts are manifested in the work context in the following way. Anxiety between social identity groups exists in society due to historical and deeply rooted tensions. One of the few places in which these groups are forced to interact is the workplace. Faultlines that exist within the organization or within work teams become activated when external forces (e.g. identity conflict in society) make subgroup distinctions highly salient. Group members "collide" when they find themselves having to work together on the same team or within the same organization. The anxiety and conflict originating in society has the potential to spill over into the organization (Lau and Murnighan, 1998; Simon and Klandermans, 2001), particularly when an event activates faultlines in the organization and social identity differences become salient.

Initially a conflict may erupt between two individuals, but if at least one party attributes the conflict to social identity group differences that resonate with historical tensions between groups and involve other people, the conflict becomes a social identity intergroup conflict. The higher the intergroup anxiety that currently exists because of the history of conflict between the two groups, the more likely it is that escalation will occur and people will begin to take sides. Escalation occurs as groups 
increasingly begin to polarize (i.e. in-group/out-group distinctions become more salient) and as attempts to communicate and/or resolve the conflict fail. When at least one group appears unwilling to change or acknowledge a problem and the other group is unwilling to concede, conflict resolution is likely to fail. Group members begin to involve outsiders (e.g. union representatives, the media) or attempt to push the issue up the chain of command within the organization.

Leadership intervention could occur at multiple points in time as the conflict escalates and more people become involved. Interventions may take the form of preventative or reactive measures. Preventative measures include actions taken to reduce the likelihood of conflict erupting or escalating and measures to reduce the potential negative impact of a future conflict. Reactive measures refer to those decisions made in the moment to ameliorate a conflict as it unfolds. Reactive measures may include apologies, group dialogue, separation of groups, education, coaching, punishments, etc. The earlier in the escalation cycle the leader can intervene, the more likely it is that conflict will be mitigated and negative implications for productivity and employee satisfaction will be minimized. In the next section, we review four strategies to prevent identity group conflicts based on Social Identity Theory: decategorization, recategorization, subcategorization and crosscutting.

\section{Overcoming identity-based conflict}

Perhaps one of the most well known and oldest strategies for reducing intergroup conflict is the contact hypothesis (Allport, 1954). The contact hypothesis states that interaction between groups will improve intergroup relations under specific conditions. Some of the conditions that should promote more positive attitudes among majority group members (Devine and Vasquez, 1998) include: (a) contact between people of equal status; (b) co-operative rather than competitive interactions; (c) institutional support such that those in positions of authority endorse integration; (d) positive outcomes of contact; (e) contact between similarly competent others; and (f) contact with a non-stereotypic other. Although numerous studies have shown that intergroup contact under such conditions can reduce stereotyping, bias, and discrimination (Stephan, 1987), the contact hypothesis has serious practical limitations in that these conditions are extremely difficult to achieve in real-world intergroup situations (Devine and Vasquez, 1998). However, early research on the contact hypothesis served as a springboard to the development of several categorization strategies based on social identity theory (Brown, 2000). Social Identity Theory predicts that individuals classify themselves and others into social categories creating in-group/ out-group distinctions that often lead to in-group bias, negative affect toward outgroup members, and intergroup conflict. Researchers thus began to consider the application of social categorization processes to create the opposite effects and reduce bias and intergroup conflict.

Decategorization proposes that contact will be most effective when interactions between individuals are not category-based, but rather person-based (Brewer and Miller, 1984). Interactions should be structured to reduce the salience of category membership and allow participants the opportunity to get to know out-group members as individuals, to disconfirm stereotypes and perceptions of the out-group as homogeneous. In decategorization, personal identity is emphasized and group identity is de-emphasized. Research on decategorization has shown that personalization can alter intergroup stereotypes, but does not always reduce prejudice, perhaps because positive interpersonal experiences do not necessarily generalize to attitudes toward the whole group (Brewer and Brown, 1998). 
Using a person-based leadership strategy is consistent with several related theories. For example, transformational leadership theory suggests that a key component of effective leadership is individualized consideration, in which the leader considers individual hopes, abilities, needs and goals, listens to individuals attentively, and fosters their development by coaching, teaching and advising (Avolio and Bass, 1995; Bass, 1997). The leader-member exchange (LMX) theory of leadership (Graen and Uhl-Bien, 1995) recommends that leaders relate to each follower as a unique individual. In Pettigrew's (1998) theory of the contact process, organizational members who are afforded the opportunity to get to know dissimilar colleagues as individuals rather than as members of the out-group may be more likely to develop close ties and empathy towards each other. The existing literature on social identity conflict, in addition to these related theories, supports the idea that decategorization can help to reduce social identity conflict.

Organizations using a decategorization strategy may try to promote positive experiences in a variety of ways. One simple way is with social gatherings or parties that include members of diverse social identity groups and provide employees with opportunities to get to know one another as individuals. Organizations may also implement decategorization strategies through the formal structure by creating an environment supportive of collegial relationships. Organizational tasks and reward structures may be configured to encourage mutually collegial relationships (Brickson, 2000). One of the interviews from a South African bank provides an example - a manager encouraging the black majority and the white minority to socialize at company events for the purpose of learning how to better get along with one another.

Recategorization also attempts to alter group member perceptions of group boundaries, but suggests that this should be accomplished by creating a common or superordinate category in which both in-group and out-group members belong. Known as the common in-group identity model (Gaertner et al., 1993), this intervention is designed to minimize attention to category differences by creating a new inclusive group identity (Brewer and Brown, 1998). In a review of the literature, Dovidio et al. (2001: 433) conclude that recategorization of a person as an in-group member rather than as an out-group member has been demonstrated to produce greater perceptions of shared beliefs, to facilitate empathic arousal and to reduce blame for negative outcomes. They argue that "recategorization reduces bias by extending the benefits of in-group favoritism to former out-group members." Recently, Lau and Murnighan (2005) suggest that when strong faultiness exists, group members might require common goals or integrative tasks to overcome their divisive subgroup structures.

For example, one interviewee spoke about an environmental school in Israel that brings together Israeli and Palestinian teens to work together on preserving common natural resources. In essence, the participants are taught to recategorize each other as stewards of a shared natural resource. Another interviewee described how members from rival gangs worked together to carry food and medical supplies to a shelter housing victims from a natural disaster. Non-profit organizations often use their mission to "save the world (or a part of it)" as a recategorization strategy. They emphasize that different groups are in this world together. In for profit organizations, concepts such as market share, winning the war for talent, and profits are often used to create a super-ordinate organizational goal. Tsui and Gutek (1999) suggest that one way to create a superordinate category in the workplace is to increase the salience, relevance, and importance of belonging to the organization as a social category for all organizational members. Thus, the organization itself becomes the all inclusive identity group. 
The subcategorization strategy argues that intergroup contact should be structured so that members of both groups have distinct but complementary roles to contribute toward a common goal (Hewstone and Brown, 1986). Ideally, this approach allows members of both groups to meet the need for distinctiveness, but also work together in a cooperative fashion to accomplish a goal. Dovidio et al. (1998) found that when two groups were equal in status but contributed different experiences or expertise to the task, bias was eliminated. The authors conclude that group differentiation and super-ordinate goals may in fact complement each other by recognizing and drawing from both group differences and group commonalities.

Haslam and Ellemers (2005) argue subcategorization works best by first allowing subgroup members to engage in activities that promote identity and then bring different groups together to build a super-ordinate understanding. Haslam et al. (2003) have offered a process model to be used in organizational contexts. In the first stage of their model, organizations identify which social identities employees use to define themselves collectively. In the second phase, subgroup caucusing, relevant subgroups within the organization develop goals that are relevant to their identities before coming together as a super-ordinate group. A series of experimental studies by Eggins and colleagues demonstrated that more positive outcomes occurred when subgroups were provided the opportunity to caucus prior to coming together as a large group than when subgroups were not given these opportunities (Eggins et al., 2002).

One practice illustrating this strategy is the use of affinity groups in organizations (Jayne and Dipboye, 2004). Many large organizations have formal networks intended to recognize the distinctiveness of a particular social identity group. For example, there are groups for women and for the non-dominant racial or ethnic groups in the society. Organizational members given the opportunity to have voice and input as members of a particular social identity group or groups, and at the same time contribute and identify with the super-ordinate goals of the organization may be examples of the subcategorization strategy in practice.

Finally, Brewer (1995) argues that social categorizations external to the organization become problematic when they are equated with organizational subcategories. For example, social categories often overlap with functional groups within the organization such that employees may be categorized as male executives and female clerical staff, or white supervisors and black assembly line workers. Brewer (1995) suggests the use of crosscutting to minimize this problem and reduce intergroup conflict. This strategy involves systematically or randomly crossing work group roles with category membership. The thinking behind this strategy is that if social identity and function do not co-vary, then it is less likely that disruptive incidents that occur between people in the workplace will be attributed to social identity group membership. However, there are practical considerations in applying crosscutting strategies that limit its use. This strategy requires all employees to be qualified to work across all levels and functions within the organization and this suggests equal access to educational opportunities in society.

For example, consider an organization in South Africa described by Booysen (2005). In accordance with the South African constitution, this organization is trying to shift the distribution of occupations such that black Africans and Afrikaners engage in similar jobs in an organization. In this case, it is not working well because the skill sets of the two groups are not sufficiently similar. Pre-Apartheid educational strategies have made it difficult to use a crosscutting strategy in the post-Apartheid world. Although it may be difficult to use a crosscutting strategy when educational opportunities have been unequal, crosscutting may be highly effective in virtual work teams. Virtual teams composed of members who are geographically dispersed may be a way 
of facilitating Chrobot-Mason et al:: Illuminating a cross-cultural leadership challenge 2019 crosscutting role assignments because they encourage networked structures and collaborative approaches to task completion among a large enough pool of workers to allow for an appropriate mix of skill level and social identity group membership (Armstrong and Cole, 1995). In one of our interviews, we learned of a crosscutting group in the US that was viewed by the organization as extremely successful. This group, composed of employees at all levels, social identity groups, and functions, acted in an advisory capacity to the HR Director with regard to benefits and other HR practices and policies. Creating this group served to reduce boundaries between the social identity groups and increased intergroup interaction.

\section{What is a leader to do?}

In the Mozambique example, the individual with the formal authority to deal with the situation is the white Senior Vice President who punished the black receptionist for her behavior. This caused the conflict to escalate and brought in the attention of the media and the government. What might have been a more effective course of action for the organization? Would any of the strategies drawn from the literature on self-categorization been of help in this collectivistic environment (Jackson, 2003)? Would implementation of these strategies have helped prevent the conflict in the first place?

Looking at the literature review from the perspective of this example illuminates a major omission in the current literature on resolving identity-based conflicts in the workplace, namely, a lack of consideration of the effectiveness of these strategies within various cultures or in culturally heterogeneous work groups. As societaldriven social identity conflict in the workplace is an international issue reflecting the local cultural-historical context, we propose that it is essential that leaders consider the cultural context in which they are attempting to bridge social identity differences (Kim et al., 2004; Triandis, 1996). Would these strategies, articulated largely by American, British and Australian authors, work in a more collectivistic environment such as sub-Saharan Africa? In fact, we consider the lack of understanding about the crosscultural appropriateness of the different strategies to be a significant gap in the existing literature and propose that certain strategies may be ineffective and counter productive in some cultures.

For example, consider this story of an organizational leader on an expatriate assignment in Zambia who unknowingly hired mostly members of the dominant tribe. Although none of her subordinates directly confronted her about this, she learned indirectly through conversation that some subordinates considered her a "tribalist." The interviewee who was British chose to handle this by approaching the head of the department in which she had done the hiring and subtly tried to show her ignorance of tribes by letting him know indirectly that she had no intent to favor the dominant tribe. When asked why she chose this strategy, she said that although her immediate reaction as a "Brit" would be to tell someone "hey this is nonsense, this has to stop", and confront the issue directly, she chose to handle the situation differently. "In Zambia you just don't tackle things head on .... You need time to talk around the point rather than directly at the point." This example illustrates the need to consider the cultural context when examining effective leadership strategies for dealing with identity based conflicts in the workplace.

We predict that organizations may experience social identity conflicts in a variety of contexts in which cultural differences must be considered. For example, a leader from one culture who is asked to lead organizational members from another culture may adopt a strategy considered unacceptable or inappropriate within the followers' 
culture. This may happen when a leader from a multinational firm assumes an expatriate assignment or becomes the leader of a multinational virtual team. Organizational problems may also arise when employees from different cultures with a history of intergroup conflict or tension are forced to work together, (e.g. creation of multinational firms, through mergers and acquisitions, outsourcing, new markets, etc.) and the leader finds him/herself faced with competing expectations of acceptable leadership practices.

Therefore, in the remaining sections of this paper, we discuss cultural values that may affect employee perceptions of the effectiveness of leadership strategies and present research propositions reflecting the moderating role of culture in the effectiveness of various leadership strategies to overcome identity based conflicts.

Cultural values At the societal level, values may be defined as shared, abstract ideas of good and desirable goals that serve as guiding principles for human behavior and that are expressed in the way social institutions (e.g. organizations) operate and function (Williams, 1968; Schwartz, 1999). The "average value priorities of societal members reflect the central thrust of their shared enculturation, independent of individual differences due to unique experiences or heredity" (Smith and Schwartz, 1997: 95). Societal-level cultural values reflect basic human issues that all societies must confront in order to regulate human activity - the relationship of the individual to the group, the response to uncertainty, the response to social inequality; the need to assure responsible social behavior; the balance between competition and action versus co-operation and adaptation in response to the natural and social world, and the orientation to time-the short-term present versus the long-term future. A number of theories has been developed to identify, articulate and measure cultural values (e.g. Hofstede, 2001; House and Global Leadership and Organizational Behavior Effectiveness Research Program, 2004; Inglehart et al., 1998; Maznevski et al., 2002; Schwartz, 1990, 1999; Smith et al., 2002; Triandis, 1995; Trompenaars and Hampden-Turner, 1998) and there is a burgeoning literature discussing the merits of each.

Within the literature on cultural values, the relationship of the individual to the group has received considerable attention (see Earley and Gibson, 1998; Gelfand et al., 2004; Kagitçibasi and Berry, 1989; Oyserman et al., 2002; Schwartz, 1994 for reviews). Several theorists have examined the relationship between the individual and the group, including Kluckhohn and Strodtbeck (1961), Hofstede (2001), House and Global Leadership and Organizational Behavior Effectiveness Research Program (2004), Triandis (1995), and Schwartz (1994). In this paper, we will focus our attention on the relationship between the individual and the group, as defined by the constructs of individualism and collectivism.

There are some key concepts relating to individualism/collectivism that are particularly relevant to this paper. First, there are significant cultural differences in the salience of group membership and the number of groups with which an individual identifies. Members of collectivist societies identify strongly with fewer social identity groups and group membership is likely to be salient and relatively fixed (Su et al., 1999; Tsui and Gutek, 1999). Smith and Long (forthcoming) suggest compared to individualist cultures, attachments to core identities in collectivist cultures are less fluid and options for self-categorization will fluctuate less because group affiliations are non-negotiable in such cultures. Additionally, group categories represent greater meaning and importance in some societies than others. For example, in India, religion is strongly related to status and in China; the family is the primary basis of self-identity (Tsui and Gutek, 1999). 
Second, members of collectivistic cultures are likely to make clearer distinctions between in-group and out-group members (Triandis, 1986). Chen et al., (1998) found evidence to suggest that people from individualistic cultures are mainly concerned with enhancing their personal sense of self and that in-group bias is based on peoples' desire for personal self-enhancement. In contrast, they found that in collectivist cultures, people exhibit in-group favoritism not as a means of enhancing their personal sense of self, but as an end in its own right. Triandis (1994) argues that conflict with out-groups is to be expected in collectivist cultures because collectivists tend to be self-sacrificing toward in-group members and generally exploitative toward outgroup members. Brewer (2001) also argues that intergroup comparisons will be less competitive in societies where individuals may ascribe to a variety of social identities, and thus have multiple avenues for meeting needs for inclusion and distinctiveness.

Finally, it is worth noting that collectivist cultures often develop in countries with relatively homogenous populations and, as a result, are likely to have homogenous organizations. However, such settings are not the area of interest for this paper, since we are concerned with social identity conflicts that occur as the result of employee interactions between ingroup and outgroup members (i.e. diverse social identity group interactions). Such conflict is likely to occur when there is at least a minimal level of heterogeneity in the organization. As a result, our discussions will focus on organizational settings in which employees from a diverse range of social identity groups meet each other, including some that may have a history of conflict within the larger society.

In the next section, we examine the impact of cultural differences on leader effectiveness in managing identity-based conflicts using the four strategies based on social identity theory. We will offer propositions to suggest that these strategies may be met with significant resistance and prove ineffective in certain cultural contexts. We rely on arguments from the cross-cultural literature which suggest that members of collectivist cultures hold an interdependent self-construal and members of individualist cultures hold an independent self-construal (Markus and Kitayama, 1991). Cultural differences in self-construals equate to an emphasis on unique individual characteristics, attributes, and preferences for individualistic cultures, and an emphasis on the group for collectivist cultures, in which the self becomes meaningful and complete only when it is considered in relationship to the collective. We also rely on arguments from the cross-cultural literature, which suggest that in-group/out-group distinctions and boundaries are more salient and less fluid in collectivist cultures than individualist cultures (Erez and Earley, 1993). This cultural distinction becomes important when leaders attempt to utilize categorization strategies that, by definition, focus on shifting ingroup/outgroup distinctions.

\section{Decategorization}

In the organizational literature, there has been a call for leaders of diverse work groups to purposefully engage in a leadership style that emphasizes decategorization, or person-based interactions rather than group-based interactions (Brickson and Brewer, 2001; Scandura and Lankau, 1996). Leaders using this strategy may focus their efforts on activities that emphasize individual identity and deemphasize group identity such as sponsoring events that encourage employees from different social identity groups to become acquainted with one another more personally or role modeling this strategy by taking time to interact personally with employees as unique individuals.

The strategy of decategorization is explicitly an individual focused approach since it strives to de-emphasize group social identity. Therefore, this strategy is consistent with the "normative imperative" in individualist cultures to express one's unique at- 
tributes and characteristics (Markus and Kitayama, 1991) and the emphasis placed on differences among employees in individualist cultures (Gelfand et al., 2004). In contrast, the preference in collectivist cultures is to express oneself in relation to others, interdependent with the larger collective group, and to place emphasis on the commonalities among organizational members. Although employees in collectivist societies tend to be highly relationship oriented and some researchers have found that personalized leadership strategies will be effective in collectivist cultures because of the preference for a relational self-concept (see Hogg et al., 2005), this strategy will likely only be effective with in-group members. Leadership strategies that attempt to promote and foster stronger relational ties with out-group members, particularly outgroup members with whom there is a history of conflict and tension will be met with strong resistance in collectivist cultures.

Hofstede (2001: 229) argues that, "In a collectivist culture, who one's friends are is predetermined by existing group ties; in an individualist society, friendships have to be specifically cultivated." Relationships between colleagues in collectivist cultures depend on whether the colleagues are seen as a member of the ingroup versus the outgroup. Colleagues who are ingroup members are treated as family members and cooperation is expected, however, outgroup members are often treated with hostility (Hofstede, 2001: 244). Triandis (1989) has argued that in-group/out-group distinctions are vitally important in collectivist cultures and that the subjective boundary of one's ingroup may be narrower in collectivist cultures. There is evidence to suggest that compared to Americans, Chinese show a greater tendency to fight with or avoid members of out-groups (Triandis et al., 1990).

In contrast, collegial relationships in individualistic cultures may be characterized as more independent of group identity, making it less likely that the strategy of decategorization would be threatening to employees. Leaders attempting to mitigate social identity conflict in collectivist cultures or with organizational members from collectivist cultures may experience significant resistance toward any strategy that attempts to de-emphasize group ties and familial-like relationships with coworkers and fosters or attempts to force personal relationships with outgroup members (members from social identity groups in which there is a history of tension and anxiety). This may be perceived as a threat to existing and valued ingroup/outgroup distinctions in collectivist cultures.

Proposition 1: Culture will moderate the negative relationship between decategorization and social identity conflict. Specifically, the decategorization strategy will be more effective at reducing social identity conflict with members of individualist cultures than members of collectivist cultures.

\section{Recategorization}

A recategorization strategy may be employed by a leader who attempts to use charisma and visionary leadership to evoke a higher sense of purpose (Bass, 1985) or to create a common enemy and thus facilitate an inclusive or super-ordinate identity among group members. Hogg and Terry (2000) argue that an effective leadership strategy is to increase social attraction and solidarity within the organization or work group by focusing on inter-organizational competition and emphasizing desirable attributes of the organization to provide positive distinctiveness (e.g. the organization's competitors in the market become the outgroup). When implemented successfully, the development of a super-ordinate identity proposed by the recategorization strategy may have very positive benefits. The creation of a common, inclusive, or super-ordinate identity involved in the recategorization strategy is consistent with the 
interdependent self-construal held by members of collectivist cultures. Members of collectivist cultures who hold more interdependent self-construals are motivated not by achieving separateness, but rather by serving the collective and thus more fully realizing one's connectedness (Markus and Kitayama, 1991). The GLOBE study contrasts cultures that are high on collectivism and individualism, suggesting collectivists emphasize relatedness with groups and are likely to put group goals ahead of personal goals (Gelfand et al., 2004). In collectivist societies, social units with common fate, common goals, and common values are centralized (Oyserman et al., 2002).

In contrast to decategorization, the emphasis on making a new more inclusive social identity salient makes recategorization fundamentally a collective process where new group boundaries are developed or boundaries that are more inclusive are encouraged and strengthened. Furthermore, conformity has been found to be higher in nations high on collectivism (Bond and Smith, 1996) and the leader is expected to play a paternalistic role and guide subordinate actions (Hofstede, 1980), therefore, members of collectivist cultures will likely conform to the super-ordinate goals set by the leader and/or organization. Assuming the super-ordinate identity is not perceived as a threat to existing social identity groups, we predict that employees from collectivistic cultures will generally be more receptive to this strategy because a collective approach encourages employees to look beyond their individual identities and needs and place the needs of the organization in the forefront. The practice of identifying with a larger group is consistent with the values of collectivist cultures, unlike the preferences of employees from more individualistic cultures in which greater emphasis and value is placed on distinguishing oneself from others.

Proposition 2: Culture will moderate the negative relationship between recategorization and social identity conflict. Specifically, recategorization will be a more effective strategy for reducing social identity conflict with members of collectivist cultures than members of individualist cultures.

Although in general, members of collectivist cultures will likely be more accepting of the recategorization strategy because it emphasizes the goals of the collective, there are circumstances in which recategorization would likely be met with resistance in collectivist cultures and acceptance in individualist cultures. For example, Haslam and Ellemers (2005) point out that the goal of the recategorization strategy is to encourage group members to cast aside their old group membership and embrace a new superordinate identity that is inclusive of members of both the in-group and outgroup. It might be argued that a leader's attempts to unite employees through superordinate goals from social identity groups with a deeply rooted history of conflict and high intergroup tension will be met with resistance by members of collectivist cultures because in-group/outgroup distinctions are more salient, fixed, and impermeable than individualist cultures (Erez and Earley, 1993). However, we would argue that recategorization will likely be accepted by members of collectivist cultures if employees identify with the organization and view the leader as a legitimate authority figure and agent of the organization.*

Sagiv and Schwartz (2000) contend that within collectivistic cultures, organizations function almost like extended families. Hofstede makes a similar argument, claiming that

In a collectivist society, the workplace itself may become an ingroup in the emotional sense of the word. ... The relationship between employer and employee is seen in moral terms. It resembles a family relationship, with mutual obligations of protection in exchange for loyalty.

(Hofstede, 2001: 237) 
Gelfand et al., (2004) suggest that in collectivist cultures, organizational members view themselves as highly interdependent with the organization. They state that "generally speaking, the sharing of the employees' identity with the organization would be so strong that the organization would become a part of members' self-identity" (Gelfand et al., 2004: 446). When organizational identity is high and the organization is viewed as an extension of the family, as is typically the case in collectivist societies, then super-ordinate goals set by the organization or the organizational leader will be embraced by members of collectivist cultures even when some proportion of employees in the work group or organization are viewed as social identity out-group members.

Additionally, recategorization may prove effective with members of individualist cultures to the extent that accomplishing super-ordinate goals yields individual rewards. As Haslam and Ellemers (2005) point out, people who primarily conceive of themselves as separate individuals can only be expected to direct their efforts toward the achievement of collective goals when this affects their individual outcomes. Therefore, the recategorization strategy will generally be more effective with members of collectivist cultures when the leader is perceived as a member of the in-group, and it will be more effective for members of individualistic cultures when collective and personal goals are congruent.

\section{Subcategorization}

Although there is support in the social identity literature for both the decategorization and recategorization strategies, recent research suggests (see Haslam and Ellemers, 2005) that subcategorization is preferable because members of different social identity groups may identify with a super-ordinate identity that also incorporates subgroup differences. In fact, some scholars have argued that neither decategorization nor recategorization will have long-lasting effects and are likely to invoke threat for nondominant groups, but that a third approach which integrates the two strategies will be more effective in reducing intergroup conflict. Subcategorization (or the mutual intergroup differentiation model) involves the nesting of subgroup identities within a super-ordinate identity (Hewstone and Brown, 1986). The goal is to structure intergroup contact so that members of both groups have distinct but complementary roles to contribute toward a common goal (Hewstone and Brown, 1986).

Hornsey and Hogg (2000a: 143) present a model of subgroup relations in which they argue that "social harmony is most likely to be achieved by maintaining, not weakening, subgroup identities, provided they are nested within a coherent super-ordinate identity." Their research (Hornsey and Hogg, 1999, 2000b) provides evidence to suggest that intergroup bias may be reduced when subgroup membership is part of a larger superordinate category. They also found that bias was strongest when only the super-ordinate category was made salient. Lau and Murnighan (2005) suggest that their research findings support the subcategorization strategy and imply that managers need to select tasks that take advantage of groups' within-subgroup inclinations when strong faultlines exist in the workplace.

Rather than give up their identities, or assimilate into a larger, dominant identity group, many diversity scholars have argued that organizations should adopt a multicultural perspective for organizational integration so that members are not forced to sacrifice an important aspect of their identity in order to succeed in their jobs (Cox, 1993: 60). This leadership strategy is a hybrid, seeking to draw on the stability of existing subcategories while unifying efforts within a larger super-ordinate identity that reaches across any existing social identities. As a result, we do not expect this ap- 
proach to be influenced systematically by either individualism or collectivism. This strategy allows both an interdependent and independent self-construal to exist and ideally rewards both. Additionally, we predict that perceived threat to identity will be low in both cultures. In collectivist cultures, perceived threat to the group will be low because organizational members are able to maintain their identity and are valued for their contributions made based on this group membership. In individualist cultures, perceived threat to the individual will be low as long as individual self-interests are met in concert with meeting the collective interests of the group through collaboration to accomplish a common goal.

Proposition 3: Culture will not moderate the negative relationship between subcategorization and social identity conflict. Subcategorization will be an effective strategy to reduce social identity conflict for members of both collectivist and individualist cultures.

The strategy of subcategorization provides a hybrid approach, preserving existing social identity groups while encouraging such groups to interact in a positive way. However, one major limitation of this approach is the conditions necessary for positive interaction, particularly if it is required that each group's area of expertise is equally valued (Dovidio et al., 1998). We were unable to think of many examples in history of social identity groups in conflict that are both separate and equal. We propose that this strategy will be effective in reducing social identity conflict in either individualistic or collectivistic cultures; however, it will be most effective if social identity conflict is moderate. If social identity conflict or intergroup anxiety and tension is high and power and status differences between groups is high, this strategy seems unlikely to decrease conflict because it is unlikely that group members will be capable of valuing the others' input.

\section{Cross-cutting}

Another strategy that leaders may explore to ensure that subgroup identities are valued within the organization is the use of crosscutting. Brewer (1995) recommends crosscutting, systematically or randomly crossing work group roles with category membership, to ensure adequate representation from various subgroups within the organization. So, for example, a project team or task force that may include representatives from various functional groups and levels of the organization should have approximately equal representation based on gender, race, religion, and other demographic attributes. The leader may facilitate the task force or create it and then leave the group to manage itself, in order to foster greater buy-in and communication across groups in conflict.

In support of this approach, Marcus-Newhall et al. (1993) found that within crosscutting groups, group members were less likely to favor their own group on post-test ratings, and less likely to differentiate among the group categories than in groups that did not involve a crosscutting structure. Additionally, Bettencourt and Dorr (1998) report that crosscutting role assignments decrease in-group bias of both minority and majority group members, compared to convergent role assignment. This strategy may be effective because it serves to reduce faultline strength within work groups. Lau and Murnighan (1998) argue that faultline strength will be strong with moderate levels of diversity but weak with high levels of diversity. Crosscutting by design ensures highly diverse work groups.

Although this strategy has proven to be successful in some organizational contexts within the United States, its use in more collectivistic cultures may be less effective. An assumption in restructuring the work group so that members of various social 
identity groups and levels of the organization work together is that the task is of primary importance and that in-group/out-group distinctions will be of secondary importance. However, as was mentioned above, in collectivist cultures, the personal relationship prevails over the task and over the company (Hofstede, 2001).

Furthermore, Hofstede writes that management in a collectivist culture is management of groups. In collectivist cultures, structuring work groups such that ethnic or other ingroup members work together is considered an effective strategy to support work productivity (Hofstede, 2001: 45). Whereas in individualistic cultures, the composition of work groups is based on individual criteria and keeping in-group members together is often unwanted and considered an ineffective managerial strategy. Harrison et al. (2000) provide evidence to suggest that organizational members in collectivist cultures will have more difficulty "adjusting to frequent shifts in workgroup and team membership, where such shifts involve the disruption and disestablishment of pre-existing in-groups formed over extended periods of time and based on friendship and other developed affiliations" (Harrison et al., 2000: 492).

Similar to the decategorization strategy, crosscutting places greater value on individual contributions and unique characteristics and therefore is more consistent with independent self-construals within individualist societies. Shifting group boundaries and attempts to create a new work group composed of both ingroup and outgroup members is likely to evoke perceptions of identity threat to employees from collectivist cultures.

Proposition 4: Culture will moderate the negative relationship between crosscutting and social identity conflict. Specifically, the crosscutting strategy will be more effective at reducing social identity conflict for members of individualist cultures than members of collectivist cultures.

\section{Conclusions and implications for research and practice}

From our discussion, many avenues for future study become apparent. Although we recognize some serious limitations in applying current research and theory on Social Identity Theory (SIT) to leadership interventions designed to prevent or mitigate the negative effects of identity-based conflict in the workplace, the literature does highlight some potential implications for leaders that are worth considering. Furthermore, we have argued for the importance of considering cultural context when adopting a categorization-based strategy to reduce social identity conflicts at work.

In Table 1, we attempt to summarize our propositions by making predictions about the effectiveness of four leadership strategies in cultures characterized as Collectivistic versus Individualistic. We believe that our integrated multidisciplinary literature review lays the foundation for a compelling research agenda.

In this paper, we have focused on the moderating role of culture in determining the effectiveness of four categorization strategies identified in the social identity theory literature. Although research and theory on conflict reduction based on social categorization has a long history, this work has received considerable criticism with regard to its applicability to organizations. Research testing social identity theory has generally been conducted using laboratory experiments, often with student samples, and thus it has been criticized for its lack of generalizability to real world settings. Further, these strategies seem difficult to implement. In particular, the decategorization and recategorization strategies described above have been criticized because they involve the abandonment of subgroup identities, which may be psychologically and practically difficult to implement when real-life groups are involved (Brown, 2000). 


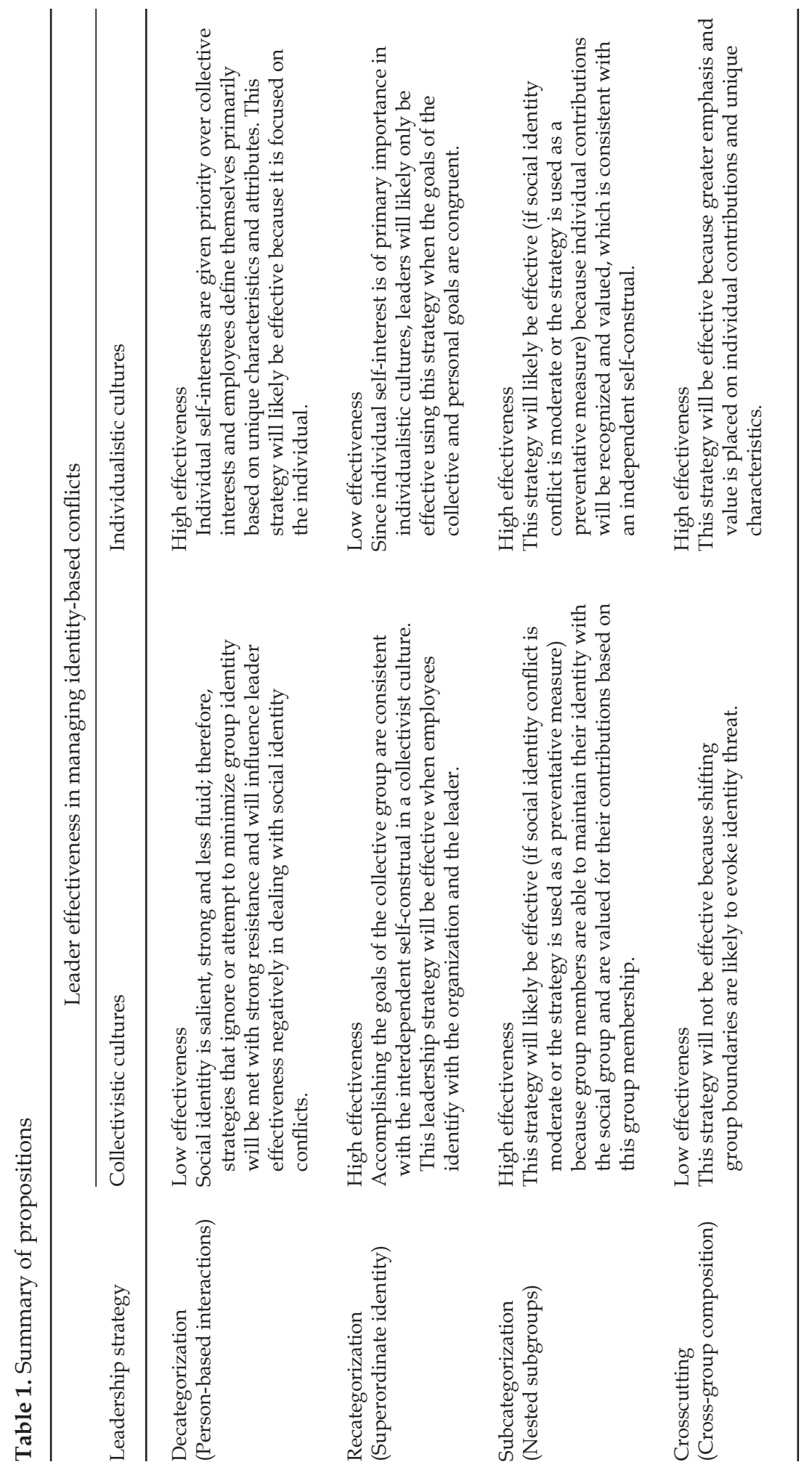


Further, there is a significant lack of knowledge as to how leaders in positions of authority in actual organizations might use these strategies. Although there is some empirical support for the social identity theory of leadership (see Hogg, 2001, for a review), much of this research has also been conducted in laboratory settings with undergraduate student populations and thus needs to be tested in the field. Reicher and Hopkins (2003) suggest that most of the focus of social identity research on leadership has been on what leads people to be endorsed as leaders by others, and there has been little focus on what leaders actually do. Thus, we concur with Reicher and Hopkins (2003: 200) that there is an "urgent need to analyze the active dimensions of leadership." Research in this area should begin to develop a more complete understanding of leadership strategies that help minimize the negative effects of identity-based conflict on information processing, employee commitment, work group cohesiveness, and ultimately performance.

Additionally, appropriate leadership strategies must be identified within specific cultural and societal contexts. In our paper, we have focused on cultural differences regarding the relationship between the individual and the group. Future research in this area should also consider the cultural dimension of power distance, which Hofstede (2001: 98) defines as, "The extent to which the less powerful members of institutions and organizations within a country expect and accept that power is distributed unequally." In high power distance cultures, the leader is likely not expected to resolve identity-based conflicts, but rather to rely on organizational policies and formal rules for maintaining order and productivity (Smith et al., 2002). Thus, power distance may be important to consider in examining when identity-based conflict will be perceived as a problem where the leader's role is to resolve the conflict, versus the perception that identity-based conflict is a natural and normal occurrence.

In addition to cultural factors, other societal factors such as economics, political and legal systems may influence leadership as well. For example, are leadership strategies differentially effective in democracies and totalitarian societies? Do laws governing, rights, obligations and opportunities, influence leadership approaches with respect to social identity differences? Does the relative wealth of a country influence leadership approaches for dealing with differences? These types of factors need to be explored in order to have a better understanding of how to deal with social identity conflicts in organizations. Organizational policies may have an impact on the management of social identity conflicts as well; for example, consider holiday, promotion and disciplinary policies. So might organizational climate. A climate emphasizing respect might have different dynamics than one emphasizing power. It is also important to look beyond the role of formal leaders and focus more generally on acts of leadership regardless of the positional authority of the person engaging in them. Finally, social identity conflicts may occur between group members who know each other well and have pre-existing friendships, or conversely, between social identity group members who do not know each other well (or perhaps at all prior to the conflict), but find themselves interacting with one another due to work demands. Even though faultlines may be activated by external forces in both cases, it seems possible that conflict is less likely to escalate and more likely to be resolved when group members involved in the conflict have pre-existing friendships or close work relationships. Therefore, various types of work relationships should be examined as well in future research.

Although we chose to focus on identifying the negative work outcomes that result from identity-based conflict, additional work in this area may suggest that there are also positive outcomes. For example, organizational learning may occur as a result of having to navigate successfully through an identity-based dispute. Argyris (1976) 
refers to this as double-loop learning, that is, learning to change underlying values and assumptions to solve problems that are ill structured and complex. There may be much to learn from organizations that generalize what they have learned in the past to implement strategies successfully that prevent future identity conflict.

Given the complexity and sensitive nature of studying identity-based conflicts in the workplace, we believe a variety of tools, methods and theoretical approaches is required to study this phenomenon adequately. A combination of inductive and deductive approaches will likely be necessary (Lee, 1999). Van de Vijver and Leung (1997) further provide a thorough discussion of the methodological issues and concerns that need to be considered in conducting cross-cultural research. Based on their work as well as others conducting cross-cultural research, we would recommend the use of a triangulated approach to study leadership strategies in various cultures, including but not limited to, questionnaires to assess responses to hypothetical situations, semistructured interviews to obtain qualitative data detailing employee and leader experiences involving identity-based conflicts, and an organizational assessment to determine organizational practices and policies.

This review points to a variety of implications for the management of human resources. At a very basic level, the leadership challenge discussed will have a major impact on numerous human resource functions. Recruiting, retention, employee development, employee relations, compensation and training are all impacted by the growing likelihood of social identity conflicts in organizations that are becoming increasingly globalized (Herriot and Scott-Jackson, 2002). Human resource systems considered effective in earlier days are likely to be called into question in organizations that are bringing groups with histories of hostilities and mistrust together in the work place. Organizations cannot underestimate the conflicts that may occur when people from different religious, national, political, ethnic and gender groups who previously have not had to work together come into contact in the workplace. These conflicts can generate serious threats to organizational effectiveness. It is in the best interest of the leader to recognize the impact of the legacies of societal conflict and distrust in the work place and take steps to manage identity based conflict.

There are two steps that organizational leaders may take to ameliorate social identity conflict in today's globalized environment. One step is simply to recognize that these conflicts may happen and to be prepared for them. Awareness is helpful because it can result in locally relevant preventative strategies such as the development of conflict resolution skills. Whether the approach is individual or collectivistic, organizations need to develop the capacity to deal with social identity conflict when it arises. Leaders need to recognize symptoms of the escalation of social identity conflicts and to recognize when a faultline is about to erupt. Preventative strategies may include policies and practices regarding the treatment of workers, decisions regarding the structure of work groups, or training in how to resolve conflict.

A second step organizational leaders may take is to develop the cultural intelligence of its members. Brislin et al. (2006) argue that cultural intelligence can be developed and that helping workers to understand what it is like to be from another identity group is one way to accomplish this. Thus, perspective taking around issues of social identity and developing an organization's ability to act in culturally intelligent ways may be a helpful way to start addressing social identity conflicts in organizations. From a human resource perspective, it is important that those in positions of leadership be able to deal with the challenge of social identity conflicts at work. Those in leadership positions will be more effective to the extent that they can adjust their behavior and approaches to reflect an understanding of the local context and feelings of different social identity groups. 
In this paper, we have reviewed the relevant literature and explored leadership in the context of social identity conflicts at work. When group identity conflicts occur in organizations, not only is work disrupted, but also group members experience substantial pain and distress that may only be remedied through significant and difficult changes in values, attitudes and behaviors. The task of leadership is to facilitate group members wrestling with these issues, such that a deeper understanding and appreciation of differences may lead group members toward a more complex view that both incorporates the diverse perspectives of the groups in question and allows the leader to move toward creating a common purpose to which all can subscribe. Thus, the organization may grow in its understanding of the needs, values, and potential contributions of employees representing various social identity groups within the organization because of the conflict. This may ultimately strengthen the organization's ability to value employee differences and to deal more effectively with identity-based disputes if or when they arise in the future.

\section{Note}

* This assumption would be true for vertical collectivist cultures but likely untrue for horizontal collectivist cultures. In HC cultures, people emphasize common goal with others but do not submit easily to authorities (Gelfand et al., 2004).

\section{References}

Allport, G. W. (1954) The Nature of Prejudice. Reading, MA: Addison-Wesley.

Amason, A. C., and Schweiger, D. M. (1997) The Effects of Conflict on Strategic Decision Making Effectiveness and Organizational Performance. In: De Dreu, C. K. W., and Van de Vliert, E. (eds.) Using Conflict in Organizations. London: Sage, pp. 105-15.

Argyris, C. (1976) Increasing Leadership Effectiveness. New York: Wiley.

Armstrong, D. J., and Cole, P. (1995) Managing Distances and Differences in Geographically Distributed Work Groups. In: Jackson, S. E., and Ruderman, M. N. (eds.) Diversity in Work Teams: Research Paradigms for a Changing Workplace. Washington, DC: American Psychological Association, pp. 187-215.

Ashforth, B. E., and Mael, F. (1989) Social Identity Theory and the Organization, Academy of Management Review, 14(1): 20-39.

Avolio, B. J., and Bass, B. M. (1995) Individual Consideration Viewed at Multiple Levels of Analysis: A Multi-level Framework for Examining the Diffusion of Transformational Leadership. Special Issue: Leadership: The multiple-level Approaches (Part I), Leadership Quarterly, 6(2): 199-218.

Bass, B. M. (1985) Leadership and Performance Beyond Expectations. New York: Free Press.

Bass, B. M. (1997) Does the Transactional-transformational Leadership Paradigm Transcend Organizational and National Boundaries?, American Psychologist, 52(2): 130-9.

Berscheid, E., and Reis, H. T. (1998) Attraction and Close Relationships. In Gilbert, D. T., Fiske, S. T., and Lindzey, G. (eds.) The Handbook of Social Psychology, 2 (4) New York: McGraw-Hill, pp. 193-281.

Bettencourt, A. B., and Dorr, N. (1998) Cooperative Interaction and Intergroup Bias: Effects of Numerical Representation and Cross-cut Role Assignment, Personality and Social Psychology Bulletin, 24(12): 1276-93.

Bond, R., and Smith, P. B. (1996) Culture and Conformity: A Meta-analysis of Studies Using Asch's (1952b, 1956) Line Judgment Task, Psychological Bulletin, 119(1): 111-37.

Booysen, L. (2005) The Leadership Challenges in Dealing with Cultural Identity Conflict in South Africa. In Hannum, K. (Chair) (ed.) Leadership Across Differences. Symposium conducted at the meeting of the International Leadership Association Amsterdam, the Netherlands. 
Brewer, M. B. (1995) Managing Diversity: The Role of Social Identities. In Jackson, S. E., and Ruderman, M. N. (eds.) Diversity in Work Teams. Washington, DC: American Psychological Association, pp. 47-68.

Brewer, M. B. (2001) Intergroup Identification and Intergroup Conflict: When Does Ingroup Love Become Outgroup Hate?. In Ashmore, R. D., Jussim, L., and Wilder, D. (eds.) Social Identity, Intergroup Conflict and Conflict Resolution. Oxford: Oxford University Press, pp. 17-41.

Brewer, M. B., and Brown, R. J. (1998) Intergroup Relations. In Gilbert, D. T., Fiske, S. T., and Lindzey, G. (eds.) The Handbook of Social Psychology, Vol. 2, (4th ed.). New York: McGraw- Hill, pp. 554-95.

Brewer, M. B., and Miller, N. (1984) Beyond the Contact Hypothesis: Theoretical Perspectives on Desegregation. In Miller, N., and Brewer, M. B. (eds.) Groups in Contact: The Psychology of Desegregation. New York: Academic Press, pp. 281-302.

Brickson, S. (2000) The Impact of Identity Orientation on Individual and Organizational Outcomes in Demographically Diverse Settings, Academy of Management Review, 25(1): 82-101.

Brickson, S., and Brewer, M. B. (2001) Identity Orientation and Intergroup Relations in Organizations. In Hogg, M., and Terry, D. (eds.) Social Identity Processes in Organizational Contexts. Philadelphia, PA: Psychology Press, pp. 49-65.

Brislin, R., Worthley, R., and MacNab, B. (2006) Cultural Intelligence: Understanding Behaviors That Serve People's Goals, Group and Organization Management, 31(1): 40-55.

Brown, R. (2000) Social Identity Theory: Past Achievements, Current Problems and Future Challenges, European Journal of Social Psychology, 30: 745-78.

Cavey, V. (2000) Fighting Among Friends: The Quaker Separation of 1827. In Coy, P. G., and Woehrle, L. M. (eds.) Social Conflicts and Collective Identities. Boston, MA: Rowman and Littlefield Publishers, Inc., pp. 133-48.

Chen, Y. R., Brockner, J., and Katz, T. (1998) Toward an Explanation of Cultural Differences in In-group Favoritism: The Role of Individual Versus Collective Primacy, Journal of Personality and Social Psychology, 75(6): 1490-502.

Chrobot-Mason, D. (2003) Developing Multicultural Competence for Managers: Same Old Leadership Skills or Something New?, The Psychologist-Manager Journal, 6(2): 5-20.

Cox, T. H. (1993) Cultural Diversity in Organizations: Theory, Research and Practice. San Francisco, CA: Berrett-Koehler Publications.

Devine, P. G., and Vasquez, K. A. (1998) The Rocky Road to Positive Intergroup Relations. In Eberhardt, J. L., and Fiske, S. T. (eds.) Confronting Racism: The Problem and the Response. Thousand Oaks, CA: Sage, pp. 234-62.

Dovidio, J. F., Gaertner, S. L., and Bachman, B. A. (2001) Racial Bias in Organizations: The Role of Group Processes in its Causes and Cures. In Turner, M. E. (ed.) Groups at Work: Theory and Research. Mahwah, NJ: Lawrence Erlbaum Associates, pp. 415-44.

Dovidio, J. F., Gaertner, S. L., and Validzic, A. (1998) Intergroup Bias: Status, Differentiation, and a Common In-group Identity, Journal of Personality and Social Psychology, 75(1): $109-20$.

Earley, P. C., and Gibson, C. B. (1998) Taking Stock in our Progress on IndividualismCollectivism: 100 Years of Solidarity and Community, Journal of Management, 24(3): 265-305.

Eggins, R. A., Haslam, S. A., and Reynolds, K. J. (2002) Social Identity and Negotiation: Subgroup Representation and Super-ordinate Consensus, Personality and Social Psychology Bulletin, 28(7): 887-99.

Erez, M., and Earley, P. C. (1993) Culture, Self-identity, and Work. New York: Oxford University Press, pp. 74-96.

Fielding, K. S., and Hogg, M. A. (1997) Social Identity, Self-categorization, and Leadership: A Field Study of Small Interactive Groups, Group Dynamics: Theory, Research, and Practice, 1(1): 39-51. 
Fisher, R. J. (1990) Needs Theory, Social Identity and an Eclectic Model of Conflict. In Burton, J. (ed.) Conflict: Human Needs Theory. New York: St Martin's Press.

Friedman, R. A., and Davidson, M. N. (2001) Managing Diversity and Second-order Conflict, The International Journal of Conflict Management, 12(2): 132-53.

Gaertner, S. L., Dovidio, J. F., Anastasio, P. A., Bachman, B. A., and Rust, M. C. (1993) The Common Ingroup Identity Model: Recategorization and the Reduction of Intergroup Bias. In Stroebe, W., and Hewstone, M. (eds.) European Review of Social Psychology (Vol. 4). Chichester: Wiley, pp. 1-26.

Gelfand, M. J., Bhawuk, D. P. S., Nishi, L. H., and Bechtold, D. J. (2004) Individualism and Collectivism. In House, R. J., Hanges, P. J., Javidan, M., Dorfman, P. W., and Gupta, V. (eds.) Culture, Leadership, and Organizations. Thousand Oaks, CA: Sage Publications, pp. 437-512.

Graen, G. B., and Uhl-Bien, M. (1995) Relationship-based Approach to Leadership: Development of Leader-member Exchange (LMX) Theory of Leadership Over 25 Years: Applying a Multilevel Multi-domain Approach, Leadership Quarterly, 6(2): 219-47.

Harrison, G. L., McKinnon, J. L., Wu, A., and Chow, C. W. (2000) Cultural Influences on Adaptation to Fluid Workgroups and Teams, Journal of International Business Studies, 31(3): 489-505.

Haslam, S. A. (2001) Psychology in Organizations: The Social Identity Approach. London: Sage.

Haslam, S. A., and Ellemers, N. (2005) Social Identity in Industrial and Organizational Psychology: Concepts, Controversies, and Contributions. In Hodgkinson, G. P., and Ford, J. K. (eds.) International Review of Industrial and Organizational Psychology (Vol. 20). Chichester: John Wiley, pp. 39-118.

Haslam, S. A., Eggins, R. A., and Reynolds, K. J. (2003) The ASPIRe Model: Actualizing Social and Personal Identity Resources to Enhance Organizational Outcomes, Journal of Occupational and Organizational Psychology, 76(1): 83-113.

Herriot, P., and Scott-Jackson, W. (2002) Globalization, Social Identities and Employment, British Journal of Management, 13(3): 249-57.

Hewstone, M., and Brown, R. J. (1986) Contact is Not Enough: An Intergroup Perspective on the Contact Hypothesis. In Hewstone, M., and Brown, R. (eds.) Contact and Conflict in Intergroup Encounters. Oxford: Blackwell, pp. 1-44.

Hicks, T. (2001) Another Look at Identity-based Conflict: The Roots of Conflict in the Psychology of Consciousness, Negotiation Journal, 17(1): 35-45.

Himes, J. S. (1980) Conflict and Conflict Management. Athens, GA: The University of Georgia Press.

Hofstede, G. H. (1980) Culture's Consequences, International Differences in Work-related Values. Beverly Hills, CA: Sage Publications.

Hofstede, G. (2001) Culture's Consequences: Comparing Values, Behaviors, Institutions, and Organizations Across Nations. Thousand Oaks, CA: Sage, pp. 209-78.

Hogg, M. A. (1996) Intragroup Processes, Group Structure and Social Identity. In Robinson, W. P. (ed.) Social Groups and Identities: The Developing Legacy of Henri Tajfel. Oxford: Butterworth-Heinemann, pp. 65-93.

Hogg, M. A. (2001) A Social Identity Theory of Leadership, Personality and Social Psychology Review, 5(3): 184-200.

Hogg, M. A., Martin, R., Epitropaki, A., Mankad, A., Svensson, A., and Weeden, K. (2005) Effective Leadership in Salient Groups: Revisiting Leader-member Exchange Theory from the Perspective of the Social Identity Theory of Leadership, Personality and Social Psychology Bulletin, 31(7): 991-1004.

Hogg, M. A., and Terry, D. J. (2000) Social Identity and Self-categorization Processes in Organizational Contexts, Academy of Management Review, 25(1): 121-40.

Hornsey, M. J., and Hogg, M. A. (1999) Subgroup Differentiation as a Response to an Overly-inclusive Group: A Test of Optimal Distinctiveness Theory, European Journal of Social Psychology, 29(4): 543-50. 
Hornsey, M. J., and Hogg, M. A. (2000a) Assimilation and Diversity: An Integrative Model of Subgroup Relations, Personality and Social Psychology Review, 4(2): 143-56.

Hornsey, M. J., and Hogg, M. A. (2000b) Subgroup Relations: A Comparison of Mutual Intergroup Differentiation and Common Ingroup Identity Models of Prejudice Reduction, Personality and Social Psychology Bulletin, 26(2): 242-56.

House, R. J., and Global Leadership and Organizational Behavior Effectiveness Research Program (2004) Culture, Leadership, and Organizations: The GLOBE Study of 62 Societies. Thousand Oaks, CA: Sage Publications.

Inglehart, R., Basáñez, M., and Menéndez Moreno, A. (1998) Human Values and Beliefs: A Cross-cultural Sourcebook: Political, Religious, Sexual, and Economic Norms in 43 Societies; Findings from the 1990-1993 World Value Survey. Ann Arbor, MI: University of Michigan Press.

Jackson, S. E. (1992) Diversity in the Workplace. New York: Guilford Press.

Jackson, T. (2003) Management and Change in Africa: Key Results. Online (April 27, 2006) at http://www.africamanagement.org

Javidan, M., Stahl, G. K., Brodbeck, F., and Wilderom, C. P. M (2005) Cross-border Transfer of Knowledge: Cultural Lessons from Project GLOBE, Academy of Management Executive, 19(2): 59-76.

Jayne, M. E., and Dipboye (2004) Leveraging Diversity to Improve Business Performance: Research Findings and Recommendations for Organizations, Human Resource Management, 43(4): 409-24.

Jehn, K. A. (1995) A Multimethod Examination of the Benefits and Detriments of Intragroup Conflict, Administrative Science Quarterly, 40(2): 256-82.

Kagitçibasi, C., and Berry, J. W. (1989) Cross-cultural Psychology - Current Research and Trends, Annual Review of Psychology, 40: 493-531.

Karim, A. U. (2003) A Developmental Progression Model for Intercultural Consciousness: A Leadership Imperative, Journal of Education for Business, 79(1): 34-9.

Katz, D. (1964) Approaches to Managing Conflict. In Kahn, R. L., and Boulding, E. (eds.) Power and Conflict in Organizations. London: Tavistock Publications.

Kim, K., Dansereau, F., Kim, I. S., and Kim, K. S. (2004) A Multiple-level Theory of Leadership: The Impact of Culture as a Moderator, Journal of Leadership and Organizational Studies, 11(1): 78-92.

Kluckhohn, C. (1951) The Study of Culture. In Lerner, D., and Lasswell, H. D. (eds.) The Policy Sciences. Stanford, CA: Stanford University Press.

Kluckhohn, F. R., and Strodtbeck, F. L. (1961) Variations in Value Orientations. Evanston, IL: Row, Peterson.

Lau, D. C., and Murnighan, J. K. (1998) Demographic Diversity and Faultlines: The Compositional Dynamics of Organizational Groups, Academy of Management Review, 23(2): $325-40$.

Lau, D. C. and Murnighan, J. K. (2005) Interactions Within Groups and Subgroups: The Effects of Demographic Faultiness, Academy of Management Journal, 48(4): 645-59.

Lee, T. W. (1999) Using Qualitative Methods in Organizational Research. Thousand Oaks, CA: Sage.

Marcus-Newhall, A., Miller, N., Holtz, R., and Brewer, M. B. (1993) Crosscutting Category Membership with Role Assignment: A Means of Reducing Intergroup Bias, British Journal of Social Psychology, 32(2): 124-46.

Markus, H. R., and Kitayama, S. (1991) Culture and the Self: Implications for Cognition, Emotion, and Motivation, Psychological Review, 98(2): 224-53.

Maznevski, M. L., DiStefano, J. J., Gomez, C. B., and Noorderhaven, N. G. (2002) Cultural Dimensions at the Individual Level of Analysis: The Cultural, International Journal of Cross Cultural Management, 2(3): 275.

Morrison, A. M. (1992) The New Leaders: Leadership Diversity in America. San Francisco, CA: Jossey-Bass Publishers. 
Northrup, T. A. (1989) The Dynamic of Identity in Personal and Social Conflict. In Kriesberg, L.,

Northrup, T. A., and Thorson, S. J. (eds.) Intractable Conflicts and Their Transformation. Syracuse, NY: Syracuse University Press, pp. 55-82.

O'Connor, P. M. G., and Quinn, L. (2004) Organizational Capacity for Leadership. In McCauley, C. D., and Van Velsor, E. (eds.) The Center for Creative Leadership Handbook of Leadership Development. San Francisco, CA: John Wiley and Sons, Inc., pp. 417-37.

Oyserman, D., Coon, H. M., and Kemmelmeier, M. (2002) Rethinking Individualism and Collectivism: Evaluation of Theoretical Assumptions and Meta-analyses, Psychological Bulletin, 128(1): 3-72.

Pettigrew, T. F. (1998) Intergroup Contact Theory, Annual Review of Psychology, 49(1): 65-85.

Powell, G. N., and Taylor, K. B. (1998) Beyond O. J. : Examining Race Relations in the Workplace, Journal of Management Education, 22(2): 208-17.

Putnam, L. L., and Wondolleck, J. (2003) Intractability: Definitions, Dimensions, and Distinctions. In Lewicki, R. J., Gray, B., and Elliott, M. (eds.) Making Sense of Intractable Environmental Conflicts. Washington, DC: Island Press.

Rahim, M. A. (2001) Managing Conflict in Organizations, (3rd ed.). Westport, CT: Quorum Books.

Reicher, S. D., and Hopkins, N. (2003) On the Science of the Art of Leadership. In van Knippenberg, D., and Hogg, M. A. (eds.) Leadership and Power: Identity Processes in Groups and Organizations. London: Sage.

Rothman, J. (1997) Resolving Identity-based Conflict in Nations, Organizations, and Communities. San Francisco, CA: Jossey-Bass.

Sagiv, L., and Schwartz, S. H. (2000) A New Look at Culture: Illustrative Applications to Role Stress and Managerial Behavior. In Ashkanasky, N. N., Wiilderon, C., and Peterson, M. F. (eds.) The Handbook of Organizational Culture and Climate. Newbury Park, CA: Sage.

Scandura, T. A., and Lankau, M. J. (1996) Developing Diverse Leaders: A Leader-member Exchange Approach, Leadership Quarterly, 7(2): 243-63.

Schwartz, S. H. (1990) Individualism-collectivism - Critique and Proposed Refinements, Journal of Cross-Cultural Psychology, 21(2): 139-57.

Schwartz, S. H. (1994) Beyond Individualism/collectivism, New Cultural Dimensions of Values. In Kim, U. H., Triandis, C., Kagitçibasi, C., Choi, S. C., and Yoon, G. (eds.) Individualism and Collectivism: Theory, Methods, and Applications. London: Sage, pp. 85-119.

Schwartz, S. H. (1999) Cultural Value Differences: Some Implications for Work, Applied Psychology: An International Review, 48(1): 23-48.

Simon, B., and Klandermans, B. (2001) Politicized Collective Identity: A Social Psychological Analysis, American Psychologist, 56(4): 319-31.

Smith, P. B., and Long, K. M. (forthcoming) Social Identity in Cross-cultural Perspective. In Brown, R., and Capozza, D. (eds.) Social Identities: Motivational, Emotional, Cultural Influences. London: Psychology Press.

Smith, P. B., Peterson, M. F., Schwartz, S. H., and colleagues (2002) Cultural Values, Sources of Guidance, and Their Relevance to Managerial Behavior: A 47 Nation Study, Journal of Cross Cultural Psychology, 33(2): 188-208.

Smith, P. B., and Schwartz, S. (1997) Values. In Berry, J. W., Segall, M. H., and Kagitçibasi, C. (eds.) Handbook of Cross-cultural Psychology. Vol. 3: Social Behavior and Applications. Boston, MA: Allyn and Bacon, pp. 7-118.

Stephan, W. G. (1987) The Contact Hypothesis in Intergroup Relations. In Hendrick, C. (ed.) Group Processes and Intergroup Relations. Review of Personality and Social Psychology, 9. Thousand Oaks, CA: Sage, pp. 13-40.

Stephan, W. G., and Stephan, C. W. (1985) Intergroup Anxiety, Journal of Social Issues, 41(3): 157-75. 
Su, S. K., Chiu, C., Hong, Y., Leung, K., Peng, K., and Morris, M. W. (1999) Self-Organization and Social Organization: US and Chinese Constructions. In Tyler, T. R., Kramer, R. M., and John, O. P. (eds.) The Psychology of the Social Self. Mahway, NJ: Lawrence Erlbaum Associates, pp. 193-222.

Triandis, H. (1986) Collectivism vs. Individualism: A Reconceptualization of a Basic Concept in Cross-cultural Psychology. In Bagley, C., and Vernma, G. (eds.) Personality, Cognition, and Values. London: Macmillan, pp. 60-95.

Triandis, H. (1989) The Self and Social Behavior in Differing Cultural Contexts, Psychological Review, 96(3): 506-20.

Triandis, H. C. (1994) Culture and Social Behavior. New York: McGraw-Hill, Inc, pp. 144-80.

Triandis, H. C. (1995) Individualism and Collectivism. Boulder, CO: Westview Press.

Triandis, H. C. (1996) The Importance of Context in the Study of Diversity. In Jackson, S. E., and Ruderman, M. N. (eds.) Diversity in Work Teams: Research Paradigms for a Changing Workplace. Washington, DC: American Psychological Association, pp. 225-33.

Triandis, H. C., McCusker, C., and Hui, C. H. (1990) Multimethod Probes of Individualism and Collectivism, Journal of Personality and Social Psychology, 74(1): 118-28.

Trompenaars, F., and Hampden-Turner, C. (1998) Riding the Waves of Culture: Understanding Diversity in Global Business (2nd edn). New York: McGraw-Hill.

Tsui, A. S., and Gutek, B. A. (1999) Demographic Differences in Organizations: Current Research and Future Directions. Lanham, MY: Lexington Books.

Turner, J. C. (1987) The Analysis of Social Influence. In Turner, J. C., Hogg, M. A., Oakes, P. J., Reicher, S. D., and Wetherell, M. S. (eds.) Rediscovering the Social Group: A Self-categorization Theory. Oxford: Blackwell, pp. 68-88.

Turner, J. C., and Giles, H. (1981) Intergroup Behavior. Oxford: Blackwell.

Van de Vijver, F., and Leung, K. (1997) Methods and Data Analysis for Cross-cultural Research. Thousand Oaks, CA: Sage Publications.

Van Velsor, E., and McCauley, C. D. (2004) Introduction: Our View of Leadership Development. In McCauley, C. D., and Van Velsor, E. (eds.) The Center for Creative Leadership Handbook of Leadership Development. San Francisco, CA: John Wiley and Sons, Inc, pp. $1-22$.

Wetherell, M. (1987) Social Identity and Group Polarization. In Turner, J. C. (ed.) Rediscovering the Social Group: A Self-categorization Theory. New York: Basil Blackwell, Inc., pp. $142-70$.

Williams, Jr., R. M. (1968) Values. In Sills, E. (ed.) International Encyclopedia of the Social Sciences. New York: Macmillan, pp. 283-7. 